\title{
Ovarian Cancer Therapeutic Opportunities
}

\section{De-Kuan Chang 1, 2*}

${ }^{1}$ Department of Cancer Immunology and Virology, Dana-Farber Cancer Institute, 450 Brookline Avenue, Boston, MA 02215, USA

${ }^{2}$ Department of Medicine, Harvard Medical School, 25 Shattuck Street, Boston, MA 02215, USA

*Corresponding author: De-Kuan Chang, Department of Cancer Immunology and Virology, Dana-Farber Cancer Institute, 450 Brookline Avenue, Boston, MA 02215, USA, E-mail: De-Kuan_Chang@DFCI.HARVARD.EDU

Received date: April 11, 2016; Accepted date: April 13, 2016; Published date: April 18, 2016

Citation: De-Kuan Chang (2016) Ovarian Cancer Therapeutic Opportunities. Reproductive Immunol Open Acc 1:9. doi: 10.21767 /2476-1974.10009

Copyright: (C) 2016 Chang DK. This is an open-access article distributed under the terms of the Creative Commons Attribution License, which permits unrestricted use, distribution, and reproduction in any medium, provided the original author and source are credited.

\section{Editorial}

Among women in the United States, ovarian cancer is the fifth leading cause of cancer deaths, accounting for approximately $5 \%$ of all cancer deaths, with an estimated 22,280 new cases this year [1]. There are 239,000 new diagnoses and 152,000 deaths from the disease in 2012 worldwide. The four most common subtypes of ovarian cancer are serous, endometrioid, clear cell, and mucinous carcinoma based on distinct clinical and biological behaviors. Over $60 \%$ of ovarian cancer cases are diagnosed at a late stage of distant metastases or invasion due to lack of effective screening for detection. Currently, the standard treatment approach for patient with ovarian cancer is surgical intervention followed by platinum-based drugs plus taxane chemotherapy [2,3]. The 5-year survival rate for ovarian cancer patients with stage III or IV disease is under $20 \%$. No effective therapy is available for relapsed or metastatic disease that has failed first-line chemotherapy [4]. However, this landscape may change because of the remarkable progress in precision medicine and cancer immunotherapy.

Malignancy is considered a multi-factorial disease and the influence of immunologic mechanisms on cancer progression and prognosis has recently received much needed attention. The role of immunotherapy in cancer treatment has been proved with beneficial effect on tumor progression by augmenting immunity through active and passive strategies. Immunotherapies for cancer treatment could be categorized into certain four types, which are therapeutic vaccines, cytokines, immune checkpoint inhibitors, and adoptive $\mathrm{T}$ cell transfer. Therapeutic vaccines are designed to treat an existing cancer by inducing the tumor-directed immunity and strengthening the natural immune response against the tumor. Cytokines, as immune modulators, are potent chemical signals that manipulate immunocyte growth and activity to generate the appropriate immune effector cells to eradicate solid tumors. Immune checkpoint inhibitors are drugs, often made of antibodies that prevent cancer cells from turning off functional anti-tumor immunocytes. Adoptive T cell transfer involves the isolation and reinfusion of potent and antigen-specific $T$ lymphocytes into patients to treat cancer.
Recent reports have demonstrated that cancer vaccine using human papillomavirus (HPV) 16 synthetic long peptide resulted in complete and partial regression of high-grade HPV16-induced vulvar intraepithelial neoplasia [5,6]. In addition, it was reported that therapeutic vaccination against HPV16 has clinical benefit and potential successful treatment in patients with high-grade premalignant lesions of the cervix [7]. Another example is that HER2 peptide-based vaccination combined with dendritic cells treatment markedly decreases HER2 expression on HER2+ breast ductal carcinoma [8]. These cases indicate that therapeutic vaccine strategies have been successful in enlarging the pool of tumor-specific $\mathrm{T}$ cells or reactivating existing tumor-specific $\mathrm{T}$ cells. However, the activated $T$ cells might encounter anergic state or failure of homing to tumor without exerting their function within the tumor, resulting in an unmet therapeutic efficacy. Nowadays, a supportive co-treatment during vaccination to achieve high immune response rates and properly polarized $\mathrm{T}$ cell immune responses has progressed in ovarian cancer treatment by combining with other therapies, such as immune checkpoint inhibitors [9-11], chemotherapy [12,13] and adoptive T cell therapy [14].

Cytokines, the messengers of the immune system, could be used to activate the immune systems to suppress tumors. The successful cytokine-based cancer therapy should directly stimulate immune effector cells within the tumor and enhance anti-tumor cytotoxic effect. Numerous animal studies have demonstrated the broad antitumor effects of cytokines and this has been further translated into clinical approaches against tumor, such as IL-2, interferon (IFN), and granulocyte macrophage colony-stimulating factor (GM-CSF, essential for generation and expansion of dendritic cell for $T$ cell activation). IL-2 is the first cytokine successfully used in clinical cancer therapy, but only effective in certain types of cancers. More recently, IL-2 has been used as a key cytokine to promote the activation and proliferation of $\mathrm{T}$ and NK cells in a combination therapy $[15,16]$. The therapeutic potential of IFN is to exert a cytostatic effect on tumor cells and promote tumor cell apoptosis $[17,18]$. Although the antitumor effect of IFN is effective against different types of tumors in animal models, its clinical outcomes show limited therapeutic index. It is believed that IFN may be an important regulator of antitumor activity mediated by other cancer therapies. Likewise, current clinical 
trial for GM-CSF is combining GM-CSF with cancer vaccine and/or immune checkpoint inhibitors to enhance antitumor immunity and achieve objective cancer regression in ovarian cancer patients $[19,20]$.

Most studies of cancer immunotherapy to date have focused on augmenting immunity through active or passive strategies. One of the most promising strategies to induce $T$ cells activation is immune checkpoint inhibitors, such as CTLA-4 blockade that has been demonstrated to improve immunity and clinical outcomes [21,22] and the programmed death 1 (PD-1)/PD-L1 interruption that has been found to achieve an immunemodulation approach in the treatment of solid tumors $[23,24]$. These important studies demonstrate that the concept of reversing immunosuppression in cancer has clinical relevance and provides further evidence that immune-based therapy will eventually find a meaningful place in the anticancer treatment armamentarium. Yet increasing evidence reveals the situation of tumor microenvironment and consistence of tumor-infiltrating $\mathrm{T}$ cells are much more complex, as we came to understand the recruitment of regulatory $T$ cells (Tregs) by ovarian cancer [25-27], with poor prognosis [28]. Although the tumor infiltrating Tregs are attenuated by anti-PD- 1 and anti-CTLA-4 antibodies [29], the immune checkpoint blockade targeted agents might represent greater therapeutic index by combining with other anti-cancer therapies, such as Treg depletion and adoptive $T$ cell transfer.

Adoptive $\mathrm{T}$ cell therapy is a promising strategy to rapidly establish tumor immunity by genetically engineered $T$ cells to harbor special antigen receptors, called chimeric antigen receptors (CARs) that allow the $T$ cells to exhibit an enormous clinical impact of tumor eradication. The other strategy to engineer $T$ cells to recognize malignant cells is to express highaffinity $T$ cell receptors (TCRs) by virus transduction. The potential for adoptive $T$ cell transfer to treat cancer has been reported marked tumor regression and long-term functional antitumor activity in cancer patients, such as CD19 CAR-T cells [30] and NY-ESO-1-reactive TCR T cells [31]. The clinical trial using adoptive $T$ cell therapy has further tested in patients with ovarian cancer and revealed the potent therapeutic efficacy [32-34]. Although the infusion of engineered T cells can improve antitumor immune response, the presence of suppressive Tregs [35] and severe off-target off-tumor toxicities [36] may not be sufficient to overcome the inhibition. The challenge of controlling $T$ cells in a therapeutic setting highlights the practical necessity to augment current adoptive transfer technology. An opportunity to raise antitumor effect for adoptive $T$ cell transfer therapy might be strategies to combine with other cancer therapies.

In conclusion, the future of immunotherapies for ovarian cancer treatment looks bright. The current successes with immunotherapeutic strategies in other cancers have indicated a better therapeutic index compared to traditional therapies and increase the survival rate of patients with malignancy. These studies and the initial data in early-phase testing (phase I and II) for ovarian cancer immunotherapies suggest the approaches may ultimately prove useful for ovarian cancer treatment. Although the complexity of tumor microenvironment and antitumor immunity still remains elusive, the research of decoding the mechanisms of tumor and immunocytes may further develop better therapeutic strategies.

\section{Reference:}

1. Stewart BW, Wild CP (2014) World Cancer Report 2014. 150 cours Albert Thomas, 69372 Lyon Cedex 08, France: WHO Press, World Health Organization, 2014:953.

2. Agarwal R, Kaye SB (2003) Ovarian cancer: strategies for overcoming resistance to chemotherapy. Nat Rev Cancer 3: 502-516.

3. DiSaia PJ, Bloss JD (2003) Treatment of ovarian cancer: new strategies. Gynecologic oncology 90: S24-32.

4. Ledermann JA, Kristeleit RS (2010) Optimal treatment for relapsing ovarian cancer. Ann Oncol 21 Suppl 7: 218-222.

5. Kenter GG, Welters MJ, Valentijn AR, Lowik MJ, Berendsvan der Meer DM, et al. (2009) Vaccination against HPV-16 oncoproteins for vulvar intraepithelial neoplasia. New England Journal of Medicine 361: 1838-1847.

6. van Poelgeest MI, Welters MJ, Vermeij R, Stynenbosch LF, Loof NM, et al. (2016) Vaccination against oncoproteins of HPV16 for non-invasive vulvar/vaginal lesions: lesion clearance is related to the strength of the T-cell response. Clinical Cancer Research clincanres 2594: 2015.

7. Trimble CL, Morrow MP, Kraynyak KA, Shen X, Dallas M, et al. (2015) Safety, efficacy, and immunogenicity of VGX-3100, a therapeutic synthetic DNA vaccine targeting human papillomavirus 16 and 18 E6 and E7 proteins for cervical intraepithelial neoplasia 2/3: a randomised, double-blind, placebo-controlled phase $2 \mathrm{~b}$ trial. Lancet 386 : 2078-2088.

8. Czerniecki BJ, Koski GK, Koldovsky U, Xu S, Cohen PA, et al. (2007) Targeting HER-2/neu in early breast cancer development using dendritic cells with staged interleukin-12 burst secretion. Cancer Research 67: 1842-1852.

9. Brahmer JR, Tykodi SS, Chow LQ, Hwu WJ, Topalian SL, et al. (2012) Safety and activity of anti-PD-L1 antibody in patients with advanced cancer. N Engl J Med 366: 2455-2465.

10. Gooden M, Lampen M, Jordanova ES, Leffers N, Trimbos JB, et al. (2011) HLA-E expression by gynecological cancers restrains tumor-infiltrating CD8âo T lymphocytes. Proc Natl Acad Sci U S A 108: 10656-10661.

11. Duraiswamy J, Kaluza KM, Freeman GJ, Coukos G (2013) Dual blockade of PD-1 and CTLA-4 combined with tumor vaccine effectively restores $\mathrm{T}$-cell rejection function in tumors. Cancer Research 73: 3591-3603.

12. Dijkgraaf EM, Santegoets SJ, Reyners AK, Goedemans R, Nijman HW, et al. (2015) A phase $1 / 2$ study combining gemcitabine, Pegintron and p53 SLP vaccine in patients with platinum-resistant ovarian cancer. Oncotarget 6: 32228-33243. 
13. Vermeij R, Leffers $N$, Hoogeboom BN, Hamming IL, Wolf R, et al. (2012) Potentiation of a p53-SLP vaccine by cyclophosphamide in ovarian cancer: a single-arm phase II study. Int J Cancer 131: E670-680.

14. Ly LV, Sluijter M, Versluis M, Luyten GP, van Stipdonk MJ, et al. (2010) Peptide vaccination after T-cell transfer causes massive clonal expansion, tumor eradication, and manageable cytokine storm. Cancer Research 70: 8339-8346.

15. Ingersoll SB, Ahmad S, McGann HC, Banks RK, Stavitzski NM, et al. (2015) Cellular therapy in combination with cytokines improves survival in a xenograft mouse model of ovarian cancer. Mol Cell Biochem 407: 281-287.

16. Pandey V, Oyer JL, Igarashi RY, Gitto SB, Copik AJ, et al. (2016) Anti-ovarian tumor response of donor peripheral blood mononuclear cells is due to infiltrating cytotoxic NK cells. Oncotarget 7: 7318-7328.

17. Kotredes KP, Gamero AM (2013) Interferons as inducers of apoptosis in malignant cells. J Interferon Cytokine Res 33: 162-170.

18. Johnson CL, Green DS, Zoon KC (2015) Human monocytes in the presence of interferons alpha2a and gamma are potent killers of serous ovarian cancer cell lines in combination with paclitaxel and carboplatin. J Interferon Cytokine Res 35: 55-62.

19. Hodi FS, Mihm MC, Soiffer RJ, Haluska FG, Butler M, et al. (2003) Biologic activity of cytotoxic T lymphocyteassociated antigen 4 antibody blockade in previously vaccinated metastatic melanoma and ovarian carcinoma patients. Proc Natl Acad Sci U S A 100: 4712-4717.

20. Hamada K, Yoshihara C, Ito T, Tani K, Tagawa M, et al. (2012) Antitumor effect of chondroitin sulfate-coated ternary granulocyte macrophage-colony-stimulating factor plasmid complex for ovarian cancer. J Gene Med 14: 120-127.

21. Duraiswamy J, Kaluza KM, Freeman GJ, Coukos G (2013) Dual blockade of PD-1 and CTLA-4 combined with tumor vaccine effectively restores T-cell rejection function in tumors. Cancer Research 73: 3591-3603.

22. Lesterhuis WJ, Salmons J, Nowak AK, Rozali EN, Khong A, et al. (2013) Synergistic effect of CTLA-4 blockade and cancer chemotherapy in the induction of anti-tumor immunity. PLoS One 8: e61895.

23. Emens LA, Kok M, Ojalvo LS (2016) Targeting the programmed cell death-1 pathway in breast and ovarian cancer. Curr Opin Obstet Gynecol 28: 142-147.

24. Guo Z, Wang X, Cheng D, Xia Z, Luan M, et al. (2014) PD-1 blockade and OX40 triggering synergistically protects against tumor growth in a murine model of ovarian cancer. PLoS One 9: e89350.

25. Chang DK, Sui J, Geng S, Muvaffak A, Bai M, et al. (2012) Humanization of an anti-CCR4 antibody that kills cutaneous
T-cell lymphoma cells and abrogates suppression by Tregulatory cells. Mol Cancer Ther 11: 2451-2461.

26. Chang DK, Peterson E, Sun J, Goudie C, Drapkin RI, et al. (2016) Anti-CCR4 monoclonal antibody enhances antitumor immunity by modulating tumor-infiltrating Tregs in an ovarian cancer xenograft humanized mouse model. Oncolmmunology 5: e1090075.

27. Curiel TJ, Coukos G, Zou L, Alvarez X, Cheng P, et al. (2004) Specific recruitment of regulatory $T$ cells in ovarian carcinoma fosters immune privilege and predicts reduced survival. Nature Medicine 10: 942-949.

28. Preston CC, Maurer MJ, Oberg AL, Visscher DW, Kalli KR, et al. (2013) The ratios of CD8+ T cells to CD4+CD25+ FOXP3+ and FOXP3- $T$ cells correlate with poor clinical outcome in human serous ovarian cancer. PLoS One 8: e80063.

29. Binder DC, Schreiber H (2014) Dual blockade of PD-1 and CTLA-4 combined with tumor vaccine effectively restores Tcell rejection function in tumors--letter. Cancer Research 74: 632-635.

30. Maude SL, Frey N, Shaw PA, Aplenc R, Barrett DM, et al. (2014) Chimeric antigen receptor $T$ cells for sustained remissions in leukemia. N Engl J Med 371: 1507-1517.

31. Robbins PF, Kassim SH, Tran TL, Crystal JS, Morgan RA, et al. (2015) A pilot trial using lymphocytes genetically engineered with an NY-ESO-1-reactive T-cell receptor: longterm follow-up and correlates with response. Clin Cancer Research; 21: 1019-1027.

32. Kershaw MH, Westwood JA, Parker LL, Wang G, Eshhar Z, et al. (2006) A phase I study on adoptive immunotherapy using gene-modified $\mathrm{T}$ cells for ovarian cancer. Clin Cancer Res 12: 6106-6115.

33. Barber A, Zhang T, DeMars LR, Conejo-Garcia J, Roby KF, et al. (2007) Chimeric NKG2D receptor-bearing $T$ cells as immunotherapy for ovarian cancer. Cancer Res 67: 5003-5008.

34. Spear P, Barber A, Sentman CL (2013) Collaboration of chimeric antigen receptor (CAR)-expressing $T$ cells and host $\mathrm{T}$ cells for optimal elimination of established ovarian tumors. Oncoimmunology 2: e23564.

35. Moon EK, Wang LC, Dolfi DV, Wilson CB, Ranganathan R, et al. (2014) Multifactorial T-cell hypofunction that is reversible can limit the efficacy of chimeric antigen receptor-transduced human $\mathrm{T}$ cells in solid tumors. Clin Cancer Research 20: 4262-4273.

36. Morgan RA, Chinnasamy N, Abate-Daga D, Gros A, Robbins $P F$, et al. (2013) Cancer regression and neurological toxicity following anti-MAGE-A3 TCR gene therapy. J Immunotherapy 36:133-151. 